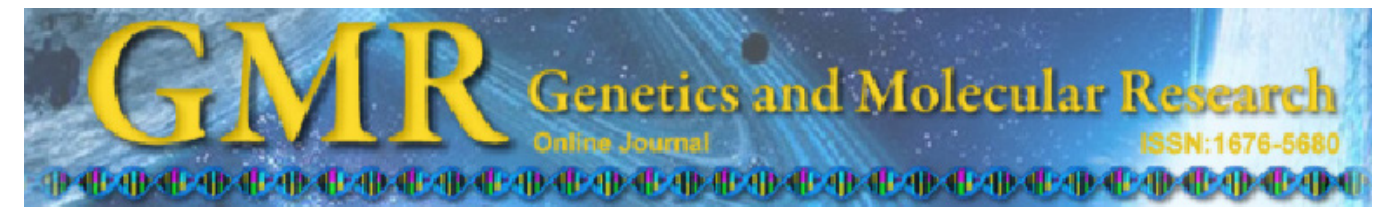

Methodology

\title{
Development of microsatellite markers for the Neotropical endemic Brazilian Guanabara frog, Euparkerella brasiliensis, through 454 shotgun pyrosequencing
}

\author{
L.A. Fusinatto ${ }^{1}$, S. Lopes ${ }^{2}$, A. Silva-Ferreira ${ }^{2}$, J. Alexandrino ${ }^{3}$, \\ C.F.B. Haddad ${ }^{4}$, C.F.D. Rocha ${ }^{1}$ and F. Sequeira ${ }^{2}$ \\ ${ }^{1}$ Departamento de Ecologia, Instituto de Biologia Roberto Alcântara Gomes, \\ Universidade do Estado do Rio de Janeiro, Rio de Janeiro, RJ, Brasil \\ ${ }^{2}$ Centro de Investigação em Biodiversidade e Recursos Genéticos, \\ Universidade do Porto, Vairão, Portugal \\ ${ }^{3}$ Departamento de Ciências Biológicas, Universidade Federal de São Paulo, \\ Diadema, SP, Brasil \\ ${ }^{4}$ Departamentos de Zoologia, Instituto de Biociências, \\ Universidade Estadual Paulista "Júlio de Mesquita Filho", Rio Claro, SP, Brasil \\ Corresponding author: L.A. Fusinatto \\ E-mail: lufusinatto@gmail.com
}

Genet. Mol. Res. 12 (1): 230-234 (2013)

Received May 21, 2012

Accepted November 5, 2012

Published January 24, 2013

DOI http://dx.doi.org/10.4238/2013.January.24.15

\begin{abstract}
The new-generation 454 GS-FLX Titanium pyrosequencing was used to isolate microsatellite markers for the Brazilian Guanabara frog, Euparkerella brasiliensis, an Atlantic forest endemic species. Three multiplex polymerase chain reaction sets were optimized for genotyping of 11 polymorphic (di- and tetranucleotide) microsatellite markers. Genetic diversity was assessed in 21 individuals from a population (Reserva Ecológica de Guapiaçu, REGUA) located
\end{abstract}


in the central region of the Rio de Janeiro State, in Brazil. The mean number of alleles per locus ranged from 3 to 12 . Observed and expected heterozygosities ranged from 0.095 to 0.905 and from 0.094 to 0.904, respectively. After using the Bonferroni correction for multiple tests, there was no evidence of linkage disequilibrium between pairs of loci but deviations for Hardy-Weinberg equilibrium were found in 4 loci. We found no evidence for allele dropouts or stuttering, but we detected the presence of null alleles at loci Eb10 and Eb36. These markers will be useful for analyses of fine-scale population structure and determination of relative effects of habitat loss and fragmentation on population genetic variability within species.

Key words: Amphibians; Atlantic forest; Euparkerella brasiliensis; Microsatellites; 454 Sequencing

\section{INTRODUCTION}

The Brazilian Atlantic forest is one of the world's richest regions for biological diversity (Laurance, 2009). However, the biome has been historically submitted to high levels of destruction and fragmentation. At present, only about $11 \%$ of the original forest cover is remained, mostly distributed in sparse and small remnants (Ribeiro et al., 2009). This level of devastation has affected several organisms. For example, most reports of Brazilian amphibian declines come from the Atlantic forest, which also shows the highest number of threatened amphibian species amongst all Brazilian regions/biomes, including the Amazon (Silvano and Segalla, 2005). Unfortunately, the consequences of habitat loss and fragmentation for amphibian populations are still poorly understood due to a lack of studies of basic organismal biology and population ecology, absence of long-term monitoring programs, and, in particular, the fact that population genetic studies have been rarely undertaken.

The Brazilian Guanabara frog, Euparkerella brasiliensis (Parker, 1926), is a miniaturized species (adults ranging from 13 to $23 \mathrm{~mm}$ in snout-vent length) endemic to the Atlantic forest and restricted to the forests of the Serra dos Órgãos mountain range and adjacent forest remnants of the Rio de Janeiro State, found at elevations of near sea level to $1000 \mathrm{~m}$ (Izecksohn, 1988). It is a terrestrial breeder with slow walking locomotion, inhabiting the leaflitter of primary and secondary forests. These morpho-ecological features, associated with the high level of habitat deterioration observed in the environment across its range, make this frog an interesting model to investigate the genetic consequences of habitat fragmentation on population structure. Here, we developed a set of microsatellite loci that will be useful to conduct fine-scale spatial genetic studies on E. brasiliensis.

\section{MATERIAL AND METHODS}

We developed a microsatellite library for E. brasiliensis from a pool of 8 individuals. We extracted DNA from toe-clipping or liver tissue samples preserved in $100 \%$ ethanol. Tissues were digested in lysis buffer solution with proteinase K. The whole genomic DNA was purified with DNeasy mini spin columns using DNeasy Blood \& Tissue kit (QIAGEN, Hilden, 
Germany), following the manufacturer protocol. We used the same methodology for samples that were genotyped.

A microsatellite-enriched DNA library was constructed by next-generation 454 GSFLX Titanium pyrosequencing carried out by Genoscreen (Lille, France), following the protocol of Malausa et al. (2011). Briefly, genomic DNA was digested with the restriction enzyme $R s a \mathrm{I}$, linked to standard adapters, purified, and enriched by hybridization with 8 microsatellite oligonucleotide probes of 2 dimers, 4 trimmers, and 2 tetramers. The enrichment was completed by capture with magnetic beads, and samples were amplified with primers corresponding to library adapters. The samples were prepared for sequencing by ligation with multiplex identifier adapters and single-stranded DNA library isolation. The single-strand template concentration was normalized by dilution and multiplexing in an equimolar mixture for the analysis of 8 samples on a $1 / 4$ GS-FLX PicoTiter plate.

The QDD program (Meglécz et al., 2010) was used for microsatellite detection and primer design. The total number of microsatellite sequences obtained was 4908, of which we selected 36 on the basis of diversity of motifs and number of repeats. Primers designed by the QDD program were chosen to amplify the selected sequences. We used the AutoDimer program (Vallone and Butler, 2004) to screen hairpin and primer-dimer interactions of all primer pairs. For each locus, the forward primer was 5'-labeled with a fluorescent dye (6-FAM, VIC, NED, or PET). We were able to amplify 14 microsatellite loci that were subsequently tested for polymorphisms. Three of 14 loci were monomorphic, and thus, were discarded. The remaining 11 polymorphic loci were used to genotype 21 individuals of $E$. brasiliensis collected at the Reserva Ecológica de Guapiaçu (REGUA), Cachoeiras de Macacu, Rio de Janeiro State, Brazil $\left(22^{\circ} 24^{\prime} 14^{\prime \prime} \mathrm{S} ; 42^{\circ} 44^{\prime} 16^{\prime \prime} \mathrm{W}\right)$. We used 3 multiplex reactions (Table 1) and polymerase chain reaction (PCR) amplifications were performed in a $10-\mu \mathrm{L}$ reaction volume containing $5 \mu \mathrm{L}$ Qiagen PCR master mix, $1 \mu \mathrm{L}$ primer mix $(0.025 \mu \mathrm{M}$ forward primer, $0.25 \mu \mathrm{M}$ reverse primer, and fluorescent dye of each primer), $3 \mu \mathrm{L}$ RNase-free water, and $1.5 \mu \mathrm{L}$ DNA template. PCR cycling conditions were as follows: initial denaturation at $95^{\circ} \mathrm{C}$, a touch-down program with 15 cycles of $95^{\circ} \mathrm{C}$ for $30 \mathrm{~s}, 65^{\circ}$ to $58^{\circ} \mathrm{C}$ for $90 \mathrm{~s}$, decreasing $0.5^{\circ} \mathrm{C}$ each cycle, and $72^{\circ} \mathrm{C}$ for $45 \mathrm{~s}$, followed by 22 cycles of $95^{\circ} \mathrm{C}$ for $30 \mathrm{~s}, 58^{\circ} \mathrm{C}$ for $90 \mathrm{~s}$, and $72^{\circ} \mathrm{C}$ for $30 \mathrm{~s}$ and 8 cycles of $95^{\circ} \mathrm{C}$ for $30 \mathrm{~s}, 58^{\circ} \mathrm{C}$ for $30 \mathrm{~s}$, and $72^{\circ} \mathrm{C}$ for $30 \mathrm{~s}$, with a final extension at $60^{\circ} \mathrm{C}$ for $30 \mathrm{~min}$. We mixed $1 \mu \mathrm{L}$ PCR product with $10 \mu \mathrm{L}$ formamide and $0.2 \mu \mathrm{L}$ internal size standard (Genescan-500 120 LIZ, ABI). Fragments were separated using an ABI prism 3130XL capillary sequencer. Alleles were scored and binned using GeneMapper v. 3.7 (Applied Biosystems).

Levels of polymorphism, deviation from Hardy-Weinberg equilibrium, and linkage disequilibrium were estimated with GENEPOP on the web v. 4.0 (Raymond and Rousset, 1995), using the default values of the Markov chain parameters.

\section{RESULTS AND DISCUSSION}

The number of alleles per loci varied from 3 to 12 and observed heterozygosity ranged from 0.095 to 0.905 (Table 1). After applying the Bonferroni correction for multiple tests (Rice, 1989), there was no evidence of linkage disequilibrium between each pair of loci, but 4 loci deviated significantly from Hardy-Weinberg equilibrium (Eb10, Eb14, Eb19, and Eb36). No evidence for large allele dropouts, stuttering, and null alleles were detected at the $99 \%$ confidence level across all loci using MICRO-CHECKER v. 2.2.3 (Van Oosterhout et al., 2004), with the exception of loci Eb10 and Eb36, for which we inferred the presence of null alleles. 
Microsatellites for Euparkerella brasiliensis

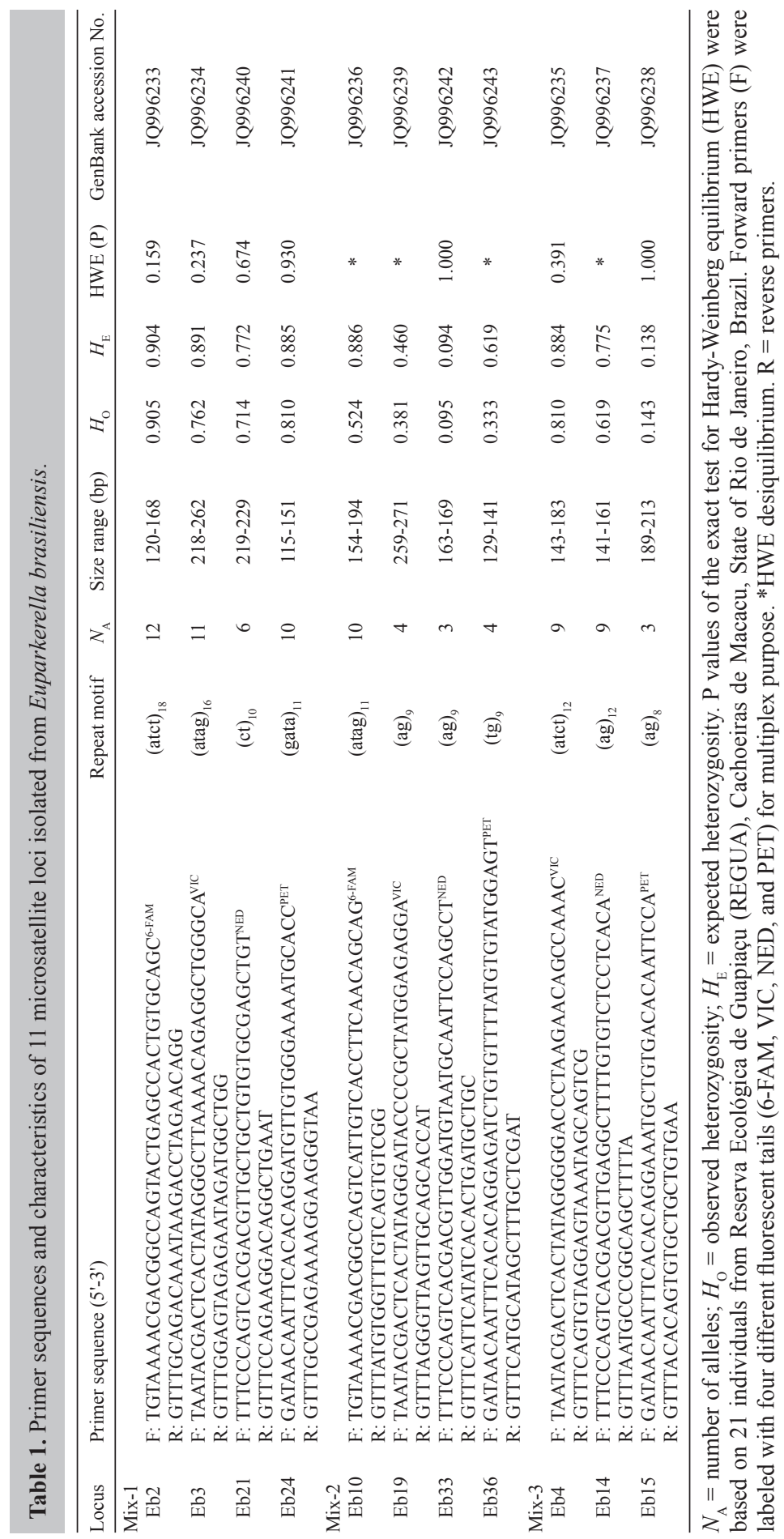

Genetics and Molecular Research 12 (1): 230-234 (2013) 


\section{ACKNOWLEDGMENTS}

We thank REGUA and Nicholas J. Locke and Raquel Locke for providing many facilities, logistical support, and for permission to work in the area. We thank Instituto Chico Mendes de Conservação da Biodiversidade (ICMBio) and Instituto Estadual do Ambiente (INEA) for collecting permits (18887 and 040/2010, respectively). L.A. Fusinatto received a doctorate fellowship from CNPq (Proc. \#142823/2009-0) and a sandwich doctorate fellowship from CAPES (Proc. \#0378/11-9). A. Silva-Ferreira is supported by a technical research grant from the research project from FCT (\#PTDC/BIA-BEC/105083/2008). J. Alexandrino was supported by FAPESP (Proc. \#2005/52727-5). C.F.B. Haddad was supported by FAPESP and CNPq. C.F.D. Rocha received grants from CNPq (Proc. \#304791/2010-5, \#470265/2010-8) and FAPERJ (Proc. \#E-26/102.404.2009). F. Sequeira is supported by a postdoctoral grant from FCT (\#SFRH/ $\mathrm{BPD} / 27134 / 2006)$.

\section{REFERENCES}

Izecksohn E (1988). Algumas considerações sobre o gênero Euparkerella, com descrição de três novas espécies (Amphibia, Anura, Leptodactylidae). Rev. Bras. Biol. 48: 59-74.

Laurance WF (2009). Conserving the hottest of the hotspots. Biol. Conserv. 142: 1137.

Malausa T, Gilles A, Meglecz E, Blanquart H, et al. (2011). High-throughput microsatellite isolation through 454 GS-FLX Titanium pyrosequencing of enriched DNA libraries. Mol. Ecol. Resour. 11: 638-644.

Meglécz E, Costedoat C, Dubut V, Gilles A, et al. (2010). QDD: a user-friendly program to select microsatellite markers and design primers from large sequencing projects. Bioinformatics 26: 403-404.

Raymond M and Rousset F (1995). GENEPOP (version 1.2): Population genetics software for exact tests and ecumenicism. J. Hered. 86: 248-249.

Ribeiro MC, Metzger JP, Matersen AC and ET AL. (2009). The Brazilian Atlantic Forest: how much is left, and how is the remaining forest distributed? Implications for conservation. Biol. Conserv. 142: 1141-1153.

Rice WR (1989). Analyzing tables of statistical tests. Evolution 43: 223-225.

Silvano DL and Segalla MV (2005). Conservação de anfíbios no Brasil. Megadiversidade 1: 79-86.

Vallone PM and Butler JM (2004). AutoDimer: a screening tool for primer-dimer and hairpin structures. Biotechniques 37: 226-231.

Van Oosterhout C, Hutchinson WF, Wills DPM and Shipley P (2004). MICRO-CHECKER: software for identifying and correcting genotyping errors in microsatellite data. Mol. Ecol. Notes 4: 535-538. 